\title{
ANALISIS GRAFIK KENDALI $n p$ YANG DISTANDARISASI UNTUK PENGENDALIAN KUALITAS DALAM PROSES PENDEK
}

\author{
Yayuk Nurkotimah dan Fachrur Rozi \\ Jurusan Matematika UIN Maulana Malik Ibrahim Malang \\ e-mail: ocy cute09@yahoo.com
}

\begin{abstract}
ABSTRAK
Salah satu grafik kendali yang sering digunakan untuk pengendalian data atribut adalah grafik kendali $p$. Grafik kendali $p$ merupakan grafik kendali proporsi ketidaksesuaian. Dalam membentuk grafik kendali $p$ dibutuhkan 20 sampai 30 subgrup. Untuk memudahkan interpretasi, maka grafik kendali perlu distandarisasi. Standarisasi dilakukan agar data berada di antara $\mu-3 \sigma$ dan $\mu+3 \sigma$. Pada praktiknya, terkadang dalam suatu proses produksi banyaknya subgrup yang diperoleh sedikit, sehingga untuk memenuhi banyaknya subgrup yang diinginkan, dibutuhkan lebih dari satu proses produksi, hal ini sering terjadi dalam kasus proses pendek. Dalam proses pendek, karena pengamatan yang diperoleh kurang dari standar untuk membentuk grafik kendali, maka perlu dilakukan penyesuaian dengan menambahkan faktor koreksi. Faktor koreksi bertujuan agar peluang standarisasi untuk proses pendek $P\left(Z_{k}{ }^{*}>U C L\right)$ dan $P\left(Z_{k}{ }^{*}<L C L\right)$ dengan $U C L=3$ dan $L C L=-3$ dapat memenuhi standar internasional yaitu mendekati 0,00135 . Dalam penelitian ini, dikembangkan grafik kendali $n p$ yang distandarisasi untuk proses pendek, di mana langkah pertama penulis akan mengkaji grafik kendali $n p$, kemudian grafik tersebut distandarisasi berdasarkan distribusi Normal standar, setelah diperoleh standarisasi maka data terebut distandarisasi untuk proses pendek. Terakhir menganalisis hasil dari standarisasi untuk proses pendek. Dengan membandingkan $P\left(Z_{k}>U C L\right)$ dan $P\left(Z_{k}<L C L\right)$ serta $P\left(Z_{k}{ }^{*}>U C L\right)$ dan $P\left(Z_{k}{ }^{*}<L C L\right)$, maka grafik kendali yang berkualitas ditunjukkan oleh grafik kendali $n p$ yang distandarisasi untuk proses pendek.
\end{abstract}

Kata kunci: faktor koreksi, grafik kendali np, proses pendek, standarisasi.

\section{PENDAHULUAN}

Pengendalian kualitas statistik merupakan teknik penyelesaian masalah yang digunakan untuk memonitor, mengendalikan, menganalisis, mengelola, dan memperbaiki produk dan proses menggunakan metode-metode statistik.

Pengendalian kualitas statistik (PKS) berhubungan dengan grafik kendali, di mana grafik kendali digunakan untuk mengendalikan proses sampel yang diperoleh. Grafik kendali yang membahas tentang sifat suatu produk disebut grafik kendali data atribut. Grafik kendali data atribut menunjukkan karakteristik kualitas yang sesuai dengan spesifikasi atau tidak sesuai dengan spesifikasi.

Untuk membuat grafik kendali $p$ dan $n p$ yang bagus, dibutuhkan 20 sampai 30 subgrup. Jika jumlah tersebut tidak terpenuhi maka grafik kendali yang dihasilkan tidak akurat. Pada penerapan grafik kendali $p$ dan $n p$ sampel yang diinginkan sulit untuk dikumpulkan dalam sekali proses produksi. Keadaan seperti ini biasanya terjadi pada proses pendek.

Proses produksi pendek adalah proses produksi yang memproduksi produk dalam jangka waktu yang pendek, sehingga tidak dapat mengambil sampel sesuai dengan kebutuhan.
Oleh karena itu, grafik kendali $p$ dan $n p$ mengambil beberapa data dari proses produksi yang berbeda yang memiliki proporsi produk cacat $(p)$ berbeda. Dari nilai $p$ yang berbeda menghasilkan batas kendali dan garis tengah yang berbeda-beda, jadi grafik kendali $p$ dan $n p$ ini harus distandarisasi.

Proses standarisasi di sini digunakan untuk mempermudah dalam menginterpretasikan grafik kendali $p$ dan $n p$. Untuk melakukan standarisai maka harus menghitung simpangan baku dari tiap-tiap sampel.

Dari penjelasan di atas maka penulis ingin mengembangkan grafik kendali $n p$ untuk distandarisasi dengan menggunakan proses pendek agar mendapatkan produk yang berkualitas.

\section{KAJIAN TEORI}

\section{Definisi 1. Ekspektasi}

Misalkan $X$ suatu peubah acak dengan distribusi peluang $f(x)$. Nilai harapan atau rata-rata $X$ adalah

bila $X$ diskrit, dan

$$
\mu=E(X)=\sum_{x} x f(x)
$$

$$
\mu=E(X)=\int_{-\infty}^{\infty} x f(x) d x
$$

bila $X$ kontinu. (Walpole dan Myers, 1995) 
Sifat 1. Ekspektasi

Bila $a$ dan $b$ konstanta, maka

$$
E(a X+b)=a E(X)+b
$$

(Walpole dan Myers , 1995)

Sifat 2. Ekspektasi

Misalkan $X$ dan $Y$ dua peubah acak yang bebas. Maka $E(X Y)=E(X) E(Y)$

(Walpole dan Myers, 1995)

Definisi 2. Variansi

Misalkan $X$ peubah acak dengan distribusi peluang $f(x)$ dan rata-rata $\mu$. Variansi $X$ adalah

$$
\sigma^{2}=E\left[(X-\mu)^{2}\right]=\sum_{x}(x-\mu)^{2} f(x)
$$

bila $X$ diskrit dan

$$
\sigma^{2}=E\left[(X-\mu)^{2}\right]=\int_{-\infty}^{\infty}(x-\mu)^{2} f(x)
$$

bila $X$ kontinu.

(Walpole dan Myers, 1995)

\section{Dalil Limit Pusat}

Misalkan $X_{1}, X_{2}, \ldots, X_{n}$ adalah sampel acak yang berasal dari distribusi yang memiliki ratarata $\mu$ dan variansi $\sigma^{2}$. Maka $Z=\frac{\sum_{i=1}^{n} X_{i}-n \mu}{\sigma \sqrt{n}}=$ $\frac{\sqrt{n}(\bar{X}-\mu)}{\sigma}$ konvergen dalam distribusi ke suatu peubah acak yang berdistribusi Normal dengan rata-rata 0 dan variansi $1(Z \rightarrow \sim N I D(0,1))$ (Dudewicz dan Mishra, 1995)

\section{Grafik Kendali Proporsi Ketidaksesuaian}

Grafik kendali $p$ didefinisikan sebagai perbandingan banyak benda yang ketidaksesuaian dalam suatu populasi dengan banyak benda keseluruhan dalam populasi itu. Andaikan $p$ merupakan proporsi ketidaksesuaian dalam proses produksi diketahui. Maka garis tengah dan batas kendalian grafik kendali dengan proporsi ketidaksesuaian adalah

$U C L=p+3 \sqrt{\frac{p(1-p)}{n}}$
$C L=p$

2) $L C L=p-3 \sqrt{\frac{p(1-p)}{n}}$

Apabila proporsi ketidaksesuaian $p$ tidak dikatahui, maka $p$ harus ditaksir dari data observasi. Prosedur yang biasa adalah memilih $m$ pengamatan pendahuluan, masing-masing berukuran $n$. Sebagai aturan umum, $m$ biasanya dipilih antara 20 sampai 25. Maka jika ada $D_{k}$ unit sampel ketidaksesuaian dalam pengamatan ke- $k$, kita hitung proporsi ketidaksesuaian dalam pengamatan ke- $k$ itu sebagai

$p_{k}=\frac{D_{k}}{n}, k=1,2,3 \ldots m$

dan rata-rata proporsi ketidaksesuaian dari seluruh pengamatan tersebut adalah

$\bar{p}=\frac{\sum_{i=1}^{m} D_{i}}{m n}=\frac{\sum_{i=1}^{m} \bar{p}_{i}}{m}, i=1,2,3, \ldots, m$

Statistik $\bar{p}$ menaksir proporsi ketidaksesuaian $p$ tidak diketahui. Garis tengah dan batas kendali grafik kendali untuk proporsi ketidaksesuaian dihitung sebagai berikut:

$U C L=\bar{p}+3 \sqrt{\frac{\bar{p}(1-\bar{p})}{n}}$
$C L=\bar{p}$

$L C L=\bar{p}-3 \sqrt{\frac{\bar{p}(1-\bar{p})}{n}}$

\section{Distribusi Normal}

Distribusi Normal adalah salah satu distribusi teoritis dari variabel random kontinu. Distribusi Normal sering disebut distribusi Gauss, sesuai nama pengembangnya, yaitu Karl Gauss pada abad ke-18, seorang ahli matematika dan astronomi. Fungsi padat peubah acak normal $X$ dengan rata-rata $\mu$ dan variansi $\sigma^{2}$ adalah

$$
f(x)=\frac{1}{\sigma \sqrt{2 \pi}} e^{-\frac{1}{2}\left(\frac{x-\mu}{\sigma}\right)^{2}},-\infty \leq x \leq \infty
$$

Karena persamaan kurva Normal tersebut di atas tergantung pada nilai $\mu$ dan $\sigma$, maka kita mempunyai bermacam-macam bentuk kurva tergantung dengan $\mu$ dan $\sigma$ tersebut. Untuk menyederhanakan dibuat kurva Normal standar. Kurva Normal standar adalah kurva Normal yang sudah diubah menjadi distribusi $Z$, di mana distribusi tersebut akan mempunyai $\mu=0$ dan $\sigma^{2}=1$. Ini dapat dilakukan melalui transformasi $Z=\frac{X-\mu}{\sigma}$.

\section{Distribusi Binomial}

\section{Definisi 3.}

Suatu peubah acak $X$ yang mempunyai distribusi Bernoulli jika (untuk suatu $p, 0 \leq p \leq 1$ ).

$$
P[X=x]=f_{X}(x)=\left\{\begin{array}{l}
p^{x}(1-p)^{1-x}, \text { bila } x=0,1 \\
0, \text { untuk yang lainnya }
\end{array}\right.
$$

(Dudewicz dan Mishra, 1995)

Sifat 3.

Bila $X$ berdistribusi Bernoulli maka $E[X]=$ $p, \operatorname{var}(X)=p(1-p)$

(Dudewicz dan Mishra, 1995)

Sifat 4. (Walpole dan Myers, 1995)

Distribusi Binomial $B(X ; n, p)$ mempunyai ratarata dan variansi $\mu=n p$ dan $\sigma^{2}=n p(1-p)$.

\section{Pendekatan Distribusi Normal Terhadap Distribusi Binomial}

Bila $X$ adalah suatu peubah acak Binomial dengan rata-rata $\mu=n p$ dan variansi $\sigma^{2}=$ $n p(1-p)$, maka bentuk pelimitan bagi sebaran adalah

$Z=\frac{X-n p}{\sqrt{n p(1-p)}}$

Untuk $n \rightarrow \infty$, adalah sebaran Normal baku

Sebaran Normal memberikan hampiran sangat baik pada sebaran Binomial bila $n$ besar dan $p$ dekat dengan $1 / 2$. Bahkan bila $n$ kecil dan $p$ 
tidak terlalu dekat pada nol dan satu, hampiran itu masih tetap baik (Walpole,1995: 197).

Seperti diketahui, distribusi Binomial bervariabel diskrit sedangkan distribusi Normal (kurva Normal) bervariabel kontinu. Karena itu, penggunaan distribusi Normal (kurva Normal) untuk menyelesaikan kasus distribusi Binomial dapat dilakukan dengan menggunakan aturan (penyesuaian), yaitu menggunakan faktor koreksi. Caranya ialah menambahkan atau mengurangi variabel $X$-nya dengan 0.5 sebagai berikut:

1. Untuk batas bawah (kiri), variabel $X$ dikurangi 0.5

2. Untuk batas atas (kanan), variabel $X$ ditambah 0.5

Dengan demikian, rumus $Z$-nya menjadi:

$$
Z=\frac{(X \pm 0.5)-n p}{\sqrt{n p(1-p)}}
$$

\section{Proses Pendek}

Proses pendek adalah proses produksi yang memproduksi produk dalam jangka waktu yang pendek atau singkat, sehingga tidak cukup waktu untuk mengambil sampel dalam jumlah yang dibutuhkan. Beberapa bursa kerja ditandai dalam produksi proses pendek, dan bursa kerja ini memproduksi beberapa bagian dari proses produksi yang kurang dari 50 unit. Pada situasi ini, dapat membuat penggunaan rutin grafik kendali terlihat seperti sebuah tantangan. Untuk menentukan batas control, suatu unit tidak dapat diproduksi dalam satu waktu. Masalah ini dapat diselesaikan dengan mudah, karena metode statistik proses kontrol paling sering diterapkan pada karakteristik dari sebuah produk, dengan memperpanjang statistik proses kontrol pada lingkungan bursa kerja dan fokus pada proses karakteristik dari setiap unit produk (Montgomery, 1990).

\section{PEMBAHASAN}

\section{Grafik kendali $n p$}

Grafik kendali $n p$ merupakan grafik kendali banyaknya unit ketidaksesuaian. Grafik kendali ini dapat dibentuk dari sebuah proses produksi. Misal ambil suatu produksi sebanyak $m$ pengamatan, di mana setiap pengamatan ke- $k$ memiliki ukuran sampel pengamatan sebanyak $n$. Misalkan dalam suatu produksi proporsi ketidaksesuaian $(p)$ diketahui dan tiap pengamatan mempunyai ukuran sampel (n) sama maka berdasarkan grafik kendali Shewhart dapat diperoleh suatu model baru yaitu:

$$
\begin{aligned}
& U C L=n p+3 \sqrt{n p(1-p)} \\
& C L=n p \\
& L C L=n p-3 \sqrt{n p(1-p)}
\end{aligned}
$$

Sedangkan jika proporsi ketidaksesuaian $(p)$ tidak diketahui dan tiap pengamatan mempunyai ukuran sampel ( $n$ ) sama maka $p$ perlu ditaksir, berdasarkan persamaan (2.4) dapat diperoleh:

$\boldsymbol{D}_{\boldsymbol{k}}=\boldsymbol{n} \boldsymbol{p}_{\boldsymbol{k}}$

Sehingga berdasarkan persamaan (2.5), $p$ dapat ditaksir oleh:

$\bar{p}=\frac{\sum_{j=1}^{m} D_{j}}{m n}=\frac{\sum_{j=1}^{m} p_{j}}{m}, j=1,2, \ldots, m$

Maka dapat diperoleh grafik kendali baru sebagai berikut:

$$
\begin{aligned}
& U C L=n \bar{p}+3 \sqrt{n \bar{p}(1-\bar{p})} \\
& C L=n \bar{p} \\
& L C L=n \bar{p}-3 \sqrt{n \bar{p}(1-\bar{p})}
\end{aligned}
$$

\section{Proses Standarisasi Grafik Kendali np}

Misalkan $X_{1}, X_{2} \ldots X_{n}$ adalah sampel acak berukuran $n$ yang berdistribusi Bernoulli dengan $\mu=p$ dan $\sigma^{2}=p(1-p)$ maka berdasarkan Dalil Limit Pusat dapat diperoleh:

$$
\begin{aligned}
Z_{k} & =\frac{\sum_{k=1}^{m} X_{k}-n \mu}{\sigma \sqrt{n}} \\
& =\frac{\boldsymbol{D}_{\boldsymbol{k}}-\boldsymbol{n p}}{\sqrt{\boldsymbol{n} \boldsymbol{p}(\mathbf{1}-\boldsymbol{p})}} \sim \boldsymbol{N I D}(\mathbf{0}, \mathbf{1})
\end{aligned}
$$

Sehingga saat proporsi ketidaksesuaian ( $p$ ) diketahui dan tiap pengamatan mempunyai ukuran sampel ( $n$ ) sama maka berdasarkan persamaan (3.4), persamaan (3.9) menjadi:

$Z_{k}=\frac{n p_{k}-n p}{\sqrt{n p(1-p)}}$

\section{Proses Standarisasi Grafik Kendali np Untuk Proses Pendek}

Misal ambil $c / n$ sebagai faktor koreksi, dengan $c$ adalah konstanta dan $n$ adalah ukuran sampel. Untuk proporsi ketidaksesuaian (p) diketahui dan ukuran sampel $(n)$ sama maka dari persamaan Lai K.Chan diperoleh:

$Z_{\boldsymbol{k}}^{*}=\frac{n p_{k}-n p-c}{\sqrt{n p(1-p)}}$

Dalam mencari perumusan proporsi ketidaksesuaian $(p)$ tidak diketahui dan ukuran sampel $(n)$ sama maka $p$ akan ditaksir oleh $\bar{p}$, dari persamaan Lai K.Chan dapat diperoleh persamaan sebagai berikut:

$$
Z_{k}=\frac{n p_{k}-n \bar{p}}{\sqrt{n \bar{p}_{k}\left(1-\bar{p}_{k}\right)}}
$$

Dengan aturan penyesuaian persamaan $Z_{k}$ dimodifikasi menjadi $Z_{k}$ dengan menambahkan konstanta $\sqrt{\frac{m}{(m-1)}}$ agar $\quad \mu_{z_{k}}=0$ dan $\sigma_{Z_{k}}^{2}=1$ sehingga didapatkan:

$Z_{k}=\sqrt{\frac{m}{(m-1)}} \frac{n p_{k}-n \bar{p}}{\sqrt{n \bar{p}(1-\bar{p})}}$ 
Sehingga berdasarkan persamaan Lai K.Chan dan persamaan (3.12) diperoleh persamaan standarisasi untuk proses pendek adalah

$Z_{k}^{*}=\sqrt{\frac{m}{(m-1)}} \frac{n p_{k}-n \bar{p}-c}{\sqrt{n \bar{p}(1-\bar{p})}}$

\section{Menganalisis Grafik Kendali np Yang Distandarisasi untuk Proses Pendek}

Dalam penelitian ini penulis meneliti 15 sampel size yang berbeda-beda mulai 50 hingga 750. Selain itu, penulis juga meneliti beberapa nilai $p$ yang berbeda-beda yaitu 0,$01 ; 0,05$; dan 0,1 . Sedangkan untuk faktor koreksi penulis menggunakan 0,$9 ; 1,1 ; 1,3$; dan 1,5 . Misal pilih $p$ $=0,05$ dan $n=750$ serta faktor koreksi 1,5 maka dapat diperoleh analisisnya sebagai berikut:

1. Setelah diplot, $P\left(Z_{k}>U C L\right)$ dan $P\left(Z_{k}<L C L\right)$ jauh dari nilai 0,00135 sedangkan $P\left(Z_{k}{ }^{*}>U C L\right)$ dan $P\left(Z_{k}{ }^{*}<L C L\right)$ berada disekitar 0,00135.

2. Suatu konstanta faktor koreksi yang baik adalah yang menghasilkan nilai $P\left(Z_{k}{ }^{*}>U C L\right)$ dan $P\left(Z_{k}{ }^{*}<L C L\right)$ yang mendekati 0,00135 . Semakin besar konstanta faktor koreksi belum tentu nilai $P\left(Z_{k}{ }^{*}>U C L\right)$ dan $P\left(Z_{k}{ }^{*}<L C L\right)$ semakin mendekati 0,00135 , begitupun semakin kecil faktor koreksi belum tentu nilai $P\left(Z_{k}{ }^{*}>U C L\right)$ dan $P\left(Z_{k}{ }^{*}<L C L\right)$ mendekati 0,00135.

Kemudian peneliti juga mengaplikasikan persamaan yang telah diperoleh pada sebuah data. Data di ambil pada proses produksi yang berbeda yakni produksi pertama 10 sampel dan produksi kedua 10 sampel. Sampel tersebut di buat dalam satu penelitian dengan tujuan untuk memenuhi standar dalam membentuk grafik kendali yakni 20 sampai 30 subgrup. Berikut ini datanya:

Tabel 1. Data Produksi dari Dua Run-Proses
\begin{tabular}{|c|c|c|}
\hline Pengamatan & $n_{k}$ & $D_{k}$ \\
\hline Produksi 1 & & \\
\hline 1 & 100 & 20 \\
\hline 2 & 100 & 25 \\
\hline 3 & 100 & 35 \\
\hline 4 & 100 & 10 \\
\hline 5 & 100 & 30 \\
\hline 6 & 100 & 5 \\
\hline 7 & 100 & 45 \\
\hline 8 & 100 & 20 \\
\hline 9 & 100 & 10 \\
\hline 10 & 100 & 10 \\
\hline Produksi 2 & & \\
\hline 1 & 100 & 5 \\
\hline 2 & 100 & 2 \\
\hline 3 & 100 & 3 \\
\hline 4 & 100 & 8 \\
\hline 5 & 100 & 4 \\
\hline 6 & 100 & 1 \\
\hline
\end{tabular}

\begin{tabular}{|c|c|c|}
\hline 7 & 100 & 2 \\
\hline 8 & 100 & 6 \\
\hline 9 & 100 & 3 \\
\hline 10 & 100 & 4 \\
\hline \multicolumn{3}{|c|}{ (Sumber: Montgomery, 1990) } \\
\hline
\end{tabular}

a. Grafik kendali $n p$

Misal ambil pengamatan ke-2 maka dari persamaan (3.6), (3.7) dan (3.8) di peroleh:

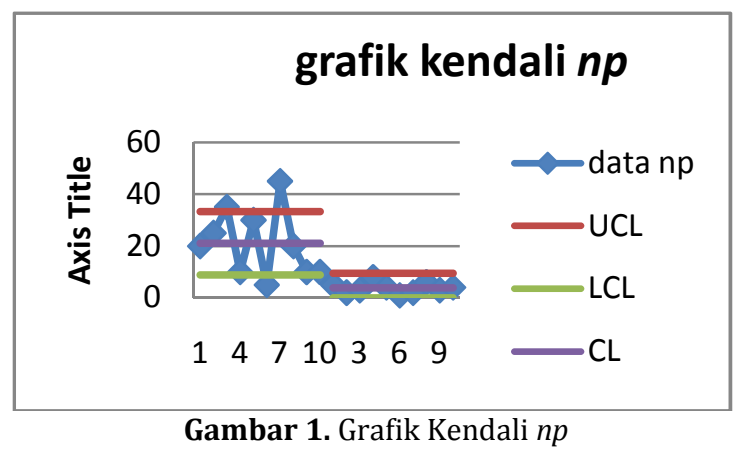

Pada grafik kendali ini, dapat dilihat bahwa masing-masing proses produksi memiliki batas atas, batas pusat dan batas bawah sendirisendiri. Untuk produksi pertama nilai yang keluar dari batas kendali ada 3 sampel sehingga yang terkendali hanya 7 sampel, namun pada produksi yang kedua semua nilai data terkendali. Hal tersebut akan sulit untuk dianalisis secara umum, oleh karena itu perlu dilakukan standarisasi.

\section{b. Grafik kendali $n p$ Yang Distandarisasi}

Misal ambil pengamatan ke-2 maka dari persamaan (3.16) didapatkan:

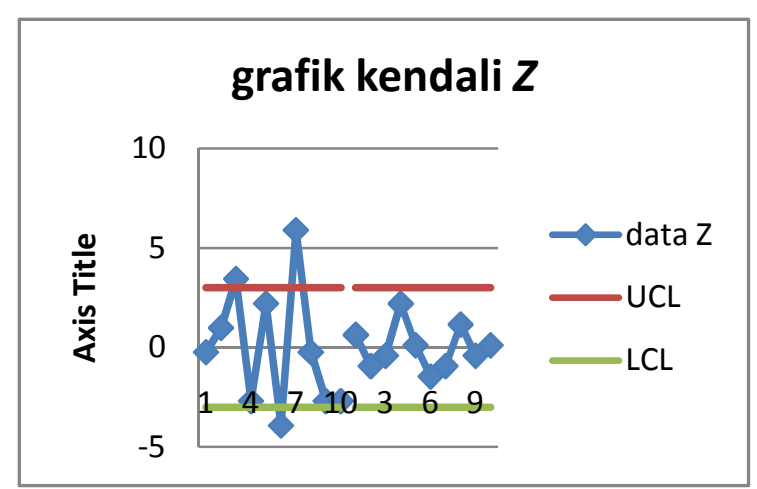

Gambar 2. Grafik kendali $n p$ yang Distandarisasi

Sedangkan untuk grafik ini, dapat diamati bahwa data terkontrol dalam grafik kendali. Namun pada data 3 dan 7 berada diluar garis kendali batas atas dan untuk data ke 6 berada diluar batas kendali bawah sehingga dari 20 data yang terkontrol hanya 17 data.

\section{c. Grafik kendali np Yang Distandarisasi Untuk Proses Pendek}

Misal ambil pengamatan ke-2 dan ambil faktor koreksi sebesar 0.5 sesuai persamaan (3.36) diperoleh: 


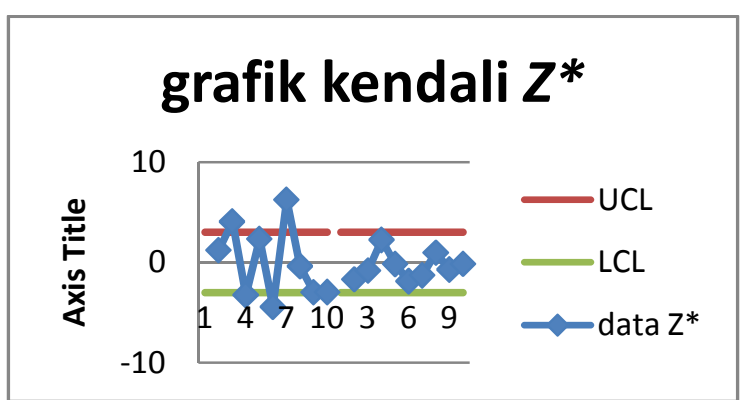

Gambar 3. Grafik Kendali $n p$ yang Distandarisasi untuk Proses Pendek

Dan untuk grafik ini dari 20 data, 16 data berada pada grafik kendali dan untuk data ke 3 dan ke 7 berada di luar batas atas kendali dan data ke 4 dan ke 6 berada di luar batas bawah kendali. Jika dibandingkan dengan grafik-grafik sebelumnya maka grafik ini merupakan grafik yang dapat mengkontrol data dengan baik.Sehingga dapat disimpulkan bahwa grafik kendali dengan faktor koreksi merupakan grafik kendali yang terbaik dari pada yang lain.

\section{PENUTUP}

Berdasarkan dari penjelasan pada bab-bab sebelumnya maka dapat disimpulkan bahwa grafik kendali $n p$ yang distandarisasi untuk proses pendek merupakan modifikasi dari grafik kendali $n p$ yang distandarisasi klasik yaitu

a. Ketika $p$ diketahui dan $n$ sama maka persamaan grafik kendali yang distandarisasi klasik ditambah faktor koreksi.

b. Ketika $p$ tidak diketahui dan $n$ sama maka persamaan grafik kendali yang distandarisasi klasik ditambah dengan faktor koreksi dan konstanta $\sqrt{\frac{m}{(m-1)}}$.

Penyesuaian tersebut dilakukan agar peluang statistik standarisasi untuk proses pendek mendekati 0,00135. Peluang statistik standarisasi lebih dari batas atas atau kurang dari batas bawah grafik kendali $n p$ untuk proses pendek dipengaruhi oleh besarnya proporsi ketidaksesuaian ( $p$ ) yang ditentukan, ukuran sampel ( $n$ ) dan faktor koreksi yang berbedabeda. Terakhir, berdasarkan aplikasi dari sebuah data dari proses yang sama, maka grafik kendali $n p$ untuk proses pendek dapat mendeteksi data dengan baik di bandingkan dengan grafik kendali yang lain.

Penelitian ini, masih dapat dikembangkan keilmuannya sehingga disarankan untuk penelitian selanjutnya agar menggunakan ukuran sampel yang berbeda-beda yang diterapkan dalam grafik kendali $u$ atau grafik kendali $c$.

\section{DAFTAR PUSTAKA}

[1] Lai K. Chan., 1996. Standardized p control charts for Short Runs. International Journal of Quality and Reliability Management. Vol. 13. No. 6. 88-95

[2] Dudewicz, Edward J dan Mishra, Satya N. 1995. Statistik Matematika Modern. Bandung: ITB

[3] Montgomery, Douglas C. 1991. Introduction to Statistical Quality Control. Singapore: Jonh Willy \&Sons,Inc

[4] Tanti Octavia.,dkk. 2000, Studi Tentang Peta Kendali $p$ Yang Distandarisasi untuk Proses Pendek Kualitas. Jurnal Teknik Industri. Vol. 2. No. $1.53-64$

[5] Walpole, Ronal dan Myers, Raymond $\mathrm{H}$. 1995. Ilmu Peluang dan Statistika untuk Insinyur dan Ilmuwan edisi keempat. Bandung: Institut Teknologi Bandung 